Original

\title{
Trace of organic sulfur compounds detected from debonded interface between transparent acrylic resin and gold alloy
}

\author{
Haruto Hiraba1), Hiroyasu Koizumi ${ }^{2,3)}$, Hiroshi Nogawa2,3), Akihisa Kodaira1), \\ Kentaro Okamura1), and Hideo Matsumura ${ }^{2,3}$ \\ 1)Division of Applied Oral Sciences, Nihon University Graduate School of Dentistry, Tokyo, Japan \\ 2)Department of Fixed Prosthodontics, Nihon University School of Dentistry, Tokyo, Japan \\ 3)Division of Advanced Dental Treatment, Dental Research Center, Nihon University School of Dentistry, \\ Tokyo, Japan
}

(Received November 2, 2016; Accepted December 12, 2016)

\begin{abstract}
The purpose of the current study was to evaluate the bonding performance of two single-liquid primers, which contained 6-(4-vinylbenzyl-n-propyl) amino-1,3,5-triazine-2,4-dithione (VTD) or 6-methacryloyloxyhexyl 2-thiouracil 5-carboxylate (MTU-6), used for bonding between metals and an acrylic resin. A gold alloy and high-purity titanium were used as adherend materials, and a transparent acrylic resin initiated with tri-n-butylborane derivative was selected as the luting material. Both adherends were treated with one of the primers and bonded with the luting material, after which shear bond strength was determined. Fourier transform infrared spectroscopy was used to analyze debonded resin specimens. Shear bond strength to gold alloy was significantly greater than that to titanium for both the VTD and MTU-6 primers. A trace of thiol structure, probably derived from VTD and MTU-6, was detected on resin surfaces debonded from gold alloy. These results indicate that the two organic sulfur compounds, which are stable in an atmospheric environment, are tautomerized into a thiol structure, thus allowing adsorption onto noble metals. In addition, the adsorbed thiol compounds contribute to chemical bonding between the acrylic
\end{abstract}

Correspondence to Dr. Hiroyasu Koizumi, Department of Fixed Prosthodontics, Nihon University School of Dentistry, 1-8-13 Kanda-Surugadai, Chiyoda-ku, Tokyo 101-8310, Japan Fax: +81-3-3219-8351 E-mail: koizumi.hiroyasu@nihon-u.ac.jp

Color figures can be viewed in the online issue at J-STAGE. doi.org/10.2334/josnusd.16-0760

DN/JST.JSTAGE/josnusd/16-0760 resin and noble metal alloy, as polymerizable adhesive functional monomers.

Keywords: adhesive; bonding; gold alloy; thiol; thione.

\section{Introduction}

Organic sulfur compounds interact directly with copper, gold, silver, and other noble metals and have therefore been used for bonding noble metal alloys. Mori and Nakamura (1) reported coating copper plates with the sulfur compound 6-(4-vinylbenzyl-n-propyl) amino-1,3,5-triazine-2,4-dithiol (VTD). A VTD acetone solution has since been used to prime dental noble metal alloys (Kojima et al., J J Dent Mater 6, 702-707, 1987), (2-8). Using infrared reflection absorption spectroscopy and surface-enhanced Raman scattering (SERS) spectroscopy, Suzuki et al. studied the structure of VTD adsorption to noble metals $(9,10)$. Ohno et al. described the structure of VTD on a Ag-Pd alloy analyzed with $\mathrm{X}$-ray photoelectron spectroscopy (11). These reports revealed that mercapto groups in VTD promote bonding to noble metals. Sulfide formation on alloy surfaces was confirmed by X-ray photoelectron spectroscopy under ultra-high vacuum conditions but not by environmental techniques such as infrared spectroscopy (12).

Another functional monomer, 6-methacryloyloxyhexyl 2-thiouracil 5-carboxylate (MTU-6), was synthesized later (13). The bonding characteristics of MTU-6 are better than those of VTD $(3,8,14,15)$. However, few studies have examined the characteristics of MTU-6 bonding to dental metal alloys. This study compared the 
Table 1 Materials assessed

\begin{tabular}{|c|c|c|c|}
\hline Material/Trade name & Manufacturer & Lot & Composition (mass \%) \\
\hline \multicolumn{4}{|l|}{ Metal, Alloy } \\
\hline Casting Gold M.C. Type IV & GC Corp., Tokyo, Japan & 0702151 & $70 \mathrm{Au}, 8 \mathrm{Ag}, 16 \mathrm{Cu}, 2 \mathrm{Pt}, 3 \mathrm{Pd}$ \\
\hline High-purity titanium & Nilaco Corp., Tokyo, Japan & 452651 & $99.9 \mathrm{Ti}$ \\
\hline \multicolumn{4}{|l|}{ Primer } \\
\hline V-Primer & Sun Medical Co., Ltd., Moriyama, Japan & FX1 & VTD, Acetone \\
\hline Metaltite & Tokuyama Dental Corp., Tokyo, Japan & 032 & MTU-6, Ethanol \\
\hline \multicolumn{4}{|l|}{ Luting material } \\
\hline Super-Bond C\&B Catalyst V & Sun Medical Co., Ltd. & LE12F & TBB, TBB-O, Hydrocarbon \\
\hline Super-Bond C\&B Clear Powder & Sun Medical Co., Ltd. & LS1 & PolyMMA \\
\hline Methyl methacrylate & Tokyo Chemical Industry Co., Ltd., Tokyo, Japan & ZJ3WJIJ & 99.8 MMA \\
\hline \multicolumn{4}{|l|}{ Reagent } \\
\hline VTD & Sun Medical Co., Ltd. & KS1 & \\
\hline Acetone & Tokyo Chemical Industry Co., Ltd. & TU7MJ & \\
\hline
\end{tabular}

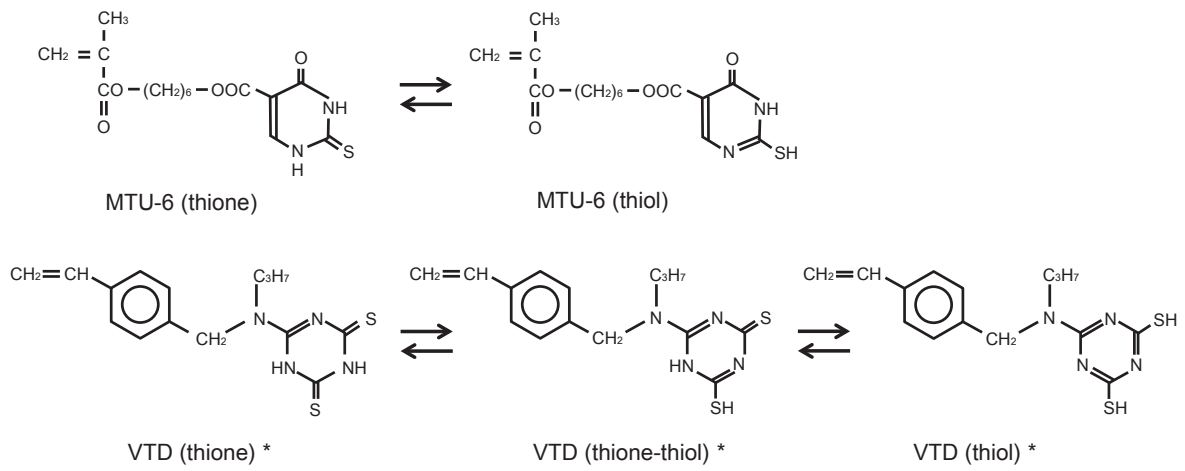

Fig. 1 Structural formulae of MTU-6 and VTD, *Suzuki et al. (9).

priming effects of VTD and MTU-6 on bonding between metals and an acrylic resin. In addition, adhesive monomers remaining on a debonded metal-resin interface were analyzed.

\section{Materials and Methods}

\section{Materials}

The materials used are described in Table 1. A gold alloy (Casting Gold M.C. Type IV, GC Corp., Tokyo, Japan) and high-purity titanium (Nilaco Corp., Tokyo, Japan) were used as adherend materials. Two single-liquid materials (V-Primer, Sun Medical Co., Ltd., Moriyama, Japan; Metaltite, Tokuyama Dental Corp., Tokyo, Japan) were used for priming adherend materials. V-Primer contains VTD in acetone; Metaltite contains MTU-6 in ethanol (Fig. 1).

A transparent acrylic resin was selected as the luting material. The resin material consists of tri- $n$-butylborane (TBB) derivative initiator (Super-Bond C\&B Catalyst V, Sun Medical Co., Ltd.), methyl methacrylate (MMA) monomer liquid (Tokyo Chemical Industry Co., Ltd., Tokyo, Japan), and poly(methyl methacrylate)
(PolyMMA) powder (Super-Bond C\&B Clear Powder, Sun Medical Co., Ltd.). In addition to the adhesive systems, VTD monomer and acetone solvent were used as the reagents for spectral analysis.

\section{Shear bond strength testing}

Disk-shaped specimens of gold alloy $(10 \mathrm{~mm}$ in diameter and $3 \mathrm{~mm}$ in thickness) were cast by using conventional lost-wax technique. The gold alloy specimens were placed for $5 \mathrm{~min}$ in an electronic furnace at $700^{\circ} \mathrm{C}$ and then quenched in cold water. The specimens were heated again to $200^{\circ} \mathrm{C}$ after being placed in an electronic furnace preheated to $450^{\circ} \mathrm{C}$ for $7 \mathrm{~min}$. Disk-shaped titanium specimens (10 $\mathrm{mm}$ in diameter and $3 \mathrm{~mm}$ in thickness) were cut from rods supplied by the manufacturer. All disk-shaped specimens were wet-ground with 2,000grit silicon carbide abrasive paper (WetorDry Sheet, $3 \mathrm{M}$ Corp., St. Paul, MN, USA) and polished with felt (TexMet 1500, Buehler, Lake Bluff, IL, USA) and a monocrystalline diamond suspension $(3-\mu \mathrm{m}$ and $1-\mu \mathrm{m}$, MetaDi, Buehler). The specimens were later ultrasonically cleaned with acetone and air-dried. 


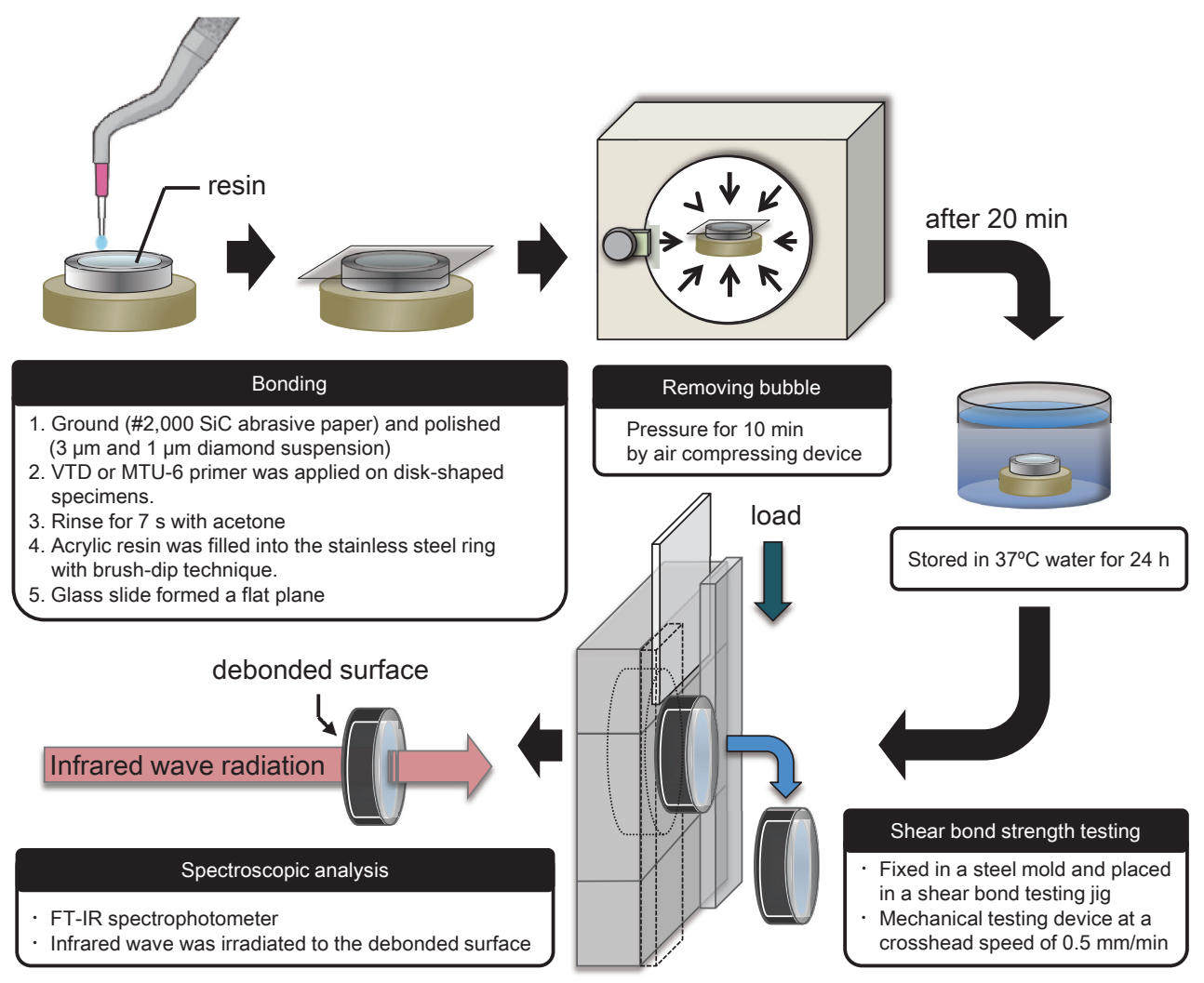

Fig. 2 Procedure for bond strength testing and spectral analysis.

V-Primer or Metaltite was applied to the adherend surface, air-dried, and rinsed for $7 \mathrm{~s}$ with acetone. A steel ring (SUS303, inner diameter of $6 \mathrm{~mm}$, height of $2 \mathrm{~mm}$, and wall thickness of $1 \mathrm{~mm}$ ) was positioned on each disk specimen, to define the bond area. The acrylic resin was filled into the ring with brush-dip technique. Specimens were placed under pressure $(0.7 \mathrm{MPa})$ for 10 min in an air-compressing device (Press technic, Yoshida Dental MFG Co., Ltd., Tokyo, Japan) and then immersed in $37^{\circ} \mathrm{C}$ distilled water for $24 \mathrm{~h}$. Eleven specimens were prepared for each adherend.

The specimens were fixed in a steel mold and placed in a testing jig to determine shear bond strength with a mechanical testing device (Type 5567, Instron, Canton, MA, USA) at a crosshead speed of $0.5 \mathrm{~mm} / \mathrm{min}$. Thus, the polymerized resin block for spectral analysis was obtained along with shear bond strength determination (Fig. 2).

After testing, the debonded surfaces were observed with an optical microscope (SZX9, Olympus, Tokyo, Japan). Failure mode was classified as follows: A, adhesive failure at the acrylic resin-alloy interface; $\mathrm{C}$, cohesive failure within the acrylic resin; and CA, combined adhesive/cohesive failure.

\section{Statistical analysis}

Shear bond strength was analyzed by using descriptive statistics (mean and standard deviation) and the statistical software package GraphPad Prism 6 (GraphPad Software Inc., La Jolla, CA, USA). The results were primarily analyzed with the D'Agostino and Pearson omnibus test, to evaluate distribution. The Bartlett test was then used for testing equality of variance. After checking normality and equality of variance, mean shear bond strength values were analyzed by two-way analysis of variance (ANOVA), to determine the effect of the primer and metal alloy as factors. When the two-way ANOVA test indicated interaction, parametric $t$-tests were used for pairwise comparison between gold alloy and titanium, and between the two primers. The significance level was set at $\alpha=0.05$.

\section{Infrared absorption spectroscopic analysis}

Transmission spectra were obtained by means of a Fourier transform infrared absorption spectrophotometer (FTIR 480 plus, Jasco Corp., Tokyo, Japan). All IR spectra were obtained from a total of 100 scans over the 4,000-400 $\mathrm{cm}^{-1}$ range, at a resolution of $2 \mathrm{~cm}^{-1}$.

IR spectra for VTD and MTU-6 were measured by using the potassium bromide $(\mathrm{KBr})$ tablet method. 
Table 2 Results of shear bond strength testing (two-way ANOVA)

\begin{tabular}{lrrrrl}
\hline Source of variation & $\%$ of total variance & $P$ value & & & \\
\hline Interaction & 0.06463 & 0.0482 & & & \\
Primer & 0.05212 & 0.0747 & & & \\
Metal alloy & 99.29000 & $P<0.0001$ & & & \\
\hline ANOVA table & Sum of squares & $d f$ & Mean square & $\mathrm{F}(\mathrm{DFn}, \mathrm{DFd})$ & $P$ value \\
\hline Interaction & 5.602 & 1 & 5.602 & $\mathrm{~F}(1,40)=4.152$ & $P=0.0482$ \\
Primer & 4.518 & 1 & 4.518 & $\mathrm{~F}(1,40)=3.349$ & $P=0.0747$ \\
Metal alloy & $8,604.000$ & 1 & $8,604.000$ & $\mathrm{~F}(1,40)=6,377$ & $P<0.001$ \\
Residual & 53.970 & 40 & 1.349 & & \\
\hline
\end{tabular}

$d f$, degree of freedom.

Table 3 Shear bond strengths (MPa), results of statistical analysis, and failure modes after shear-bond testing

\begin{tabular}{cccccccc}
\hline \multirow{2}{*}{ Primer } & \multicolumn{5}{c}{ Gold alloy } & \multicolumn{3}{c}{ Titanium } & \multirow{2}{*}{ Gold alloy and titanium } \\
\cline { 2 - 6 } & Mean (SD) & A & CA & Mean (SD) & A & CA nn & \\
\hline VTD & $27.8(1.5)^{\mathrm{a}}$ & 0 & 11 & $0.6(0.2)^{\mathrm{b}}$ & 11 & 0 & $P<0.0001$ \\
MTU-6 & $29.2(1.6)^{\mathrm{a}}$ & 0 & 11 & $0.5(0.3)^{\mathrm{b}}$ & 11 & 0 & $P<0.0001$ \\
\hline$n=11 ; \mathrm{SD}$, Standard deviation. Identical superscript letters indicate that the difference between the two priming conditions is not \\
significant $(P>0.05)$. A, adhesive failure at acrylic resin-metal interface; CA, combined adhesive/cohesive failure.
\end{tabular}

MTU-6 was procured by vaporization of the Metaltite solvent. The VTD tablet was prepared by mixing 100 $\mathrm{mg} \mathrm{KBr}$ and $0.5 \mathrm{mg} \mathrm{VTD}$, and the MTU-6 tablet was prepared by mixing $100 \mathrm{mg} \mathrm{KBr}$ and $0.4 \mathrm{mg}$ MTU-6. The IR spectra of MMA were determined with the liquid-film method, and spectra of polymerized acrylic resin were obtained from debonded specimens (Fig. 2). The results were compared with those of previous reports $(1,10,12,16)$ and with reference compounds $(17)$.

\section{Results}

\section{Shear bond strength}

The D'Agostino and Pearson omnibus test showed that the results of shear bond strength testing were normally distributed. Additionally, the validity of equal variance assumptions of bond strength values was confirmed by the Bartlett test $(P>0.05)$. Parametric statistical procedures were thus selected. Two-way ANOVA revealed a significant interaction between the metal alloy factors $(P$ $<0.001$; Table 2). Hence, $t$-tests were used for pairwise comparison between gold alloy and titanium, and to analyze differences between the two priming conditions (Table 3).

The results of the shear bond strength tests are summarized in Table 3. Shear bond strength was significantly higher for gold alloy treated with VTD primer (27.8 $\mathrm{MPa}$ ) than for titanium (0.6 MPa). In addition, shear bond strength was significantly higher for gold alloy treated with MTU-6 primer (29.2 MPa) than for titanium $(0.5 \mathrm{MPa})$. The difference in bond strength between the two priming conditions was not significant for either adherend material $(P>0.05)$. The results of failure mode analysis are shown in Table 3. No specimen exhibited cohesive failure under any experimental condition. Combined adhesive/cohesive failure was detected in the gold alloy groups, and adhesive failure was detected in the titanium groups.

Figure 3A shows a typical polished gold alloy surface before testing. Figure 3B shows a debonded gold alloy surface treated with VTD primer before bonding. This surface shows combined adhesive/cohesive failure. Figure $3 \mathrm{C}$ shows a debonded surface exhibiting partial cohesive failure within the resin material.

\section{Infrared absorption spectra}

Figure 4A shows the IR spectra of the VTD monomer. The spectra exhibited peaks indicating a thione structure. Specifically, peaks were seen at 1,535, 1,281, 1,191, 1,145 , and $462 \mathrm{~cm}^{-1}$, which are derived from $\mathrm{C}=\mathrm{S}$ stretching (Table 4). In addition, N-H stretching at 3,411 and $3,111 \mathrm{~cm}^{-1}$ were observed (Table 4). These peaks indicate that VTD has a thione structure. Figure 4B shows the IR spectra of the MMA monomer, and Fig. 4C shows the IR spectra of the polymerized acrylic resin.

Figures 4D and 4E show the IR spectra of the debonded resin block. Although the $1,558 \mathrm{~cm}^{-1}$ peak derived from the triazine dithiol structure (10) was not detected in the VTD monomer, it was present in acrylic resin specimens debonded from gold alloy. The trace peak at $656 \mathrm{~cm}^{-1}$ is probably derived from C-S stretching of VTD (Table 4). The absorption based on vinyl groups at 988 and 904 $\mathrm{cm}^{-1}$ disappeared from the polymerized resin specimen. Detection of 1,558 and $656 \mathrm{~cm}^{-1}$ peaks at the debonded resin surface indicate that VTD was adsorbed on gold 
Table 4 Band assignments for the IR spectra of VTD and organic compounds

\begin{tabular}{|c|c|c|c|c|}
\hline \multirow{2}{*}{\multicolumn{3}{|c|}{ Assignment }} & \multicolumn{2}{|r|}{ Wavenumber $\left(\mathrm{cm}^{-1}\right)$} \\
\hline & & & VTD monomer & Acrylic resin debonded from gold alloy \\
\hline 1,4-Benzene & & $\gamma \mathrm{CH}$ & 822 & \\
\hline Aromatic structure & & $v(\mathrm{C}=\mathrm{C})$ & 1,487 & 1,505 \\
\hline Triazine dithiol* & & $v(\mathrm{C}=\mathrm{C})$ & & 1,558 \\
\hline Amino group** & $>\mathrm{NH}$ & $v(\mathrm{~N}-\mathrm{H})$ & 3,111 & \\
\hline Amino group & $>\mathrm{NH}$ & $v(\mathrm{~N}-\mathrm{H})$ & 3,411 & \\
\hline Amino group & $>\mathrm{NH}$ & $\delta(\mathrm{N}-\mathrm{H})$ & & 1,652 \\
\hline Amino group & $-\mathrm{C}=\mathrm{N}(+\mathrm{H})-$ & $v(\mathrm{C}=\mathrm{N})$ & & 1,683 \\
\hline Thioketone*** & $-\mathrm{C}=\mathrm{S}$ & $v(\mathrm{C}=\mathrm{S})$ & 462 & \\
\hline Thiouredide** & $-\mathrm{NH}-\mathrm{C}(=\mathrm{S})-$ & $v(\mathrm{C}=\mathrm{S})$ & 1,145 & \\
\hline Thiouredide** & $-\mathrm{NH}-\mathrm{C}(=\mathrm{S})-$ & $v(\mathrm{C}=\mathrm{S})$ & 1,535 & \\
\hline Thioureido group & $\mathrm{N}-\mathrm{CS}-\mathrm{N}$ & $v(\mathrm{C}=\mathrm{S})$ & 1,191 & \\
\hline Thioureido group & $\mathrm{N}-\mathrm{CS}-\mathrm{N}$ & $v(\mathrm{C}=\mathrm{S})$ & 1,281 & \\
\hline Thiol & $-\mathrm{C}-\mathrm{SH}$ & $v(\mathrm{C}-\mathrm{S})$ & & 656 \\
\hline $\begin{array}{l}\text { Methyl group, } \\
\text { Methylene group** }\end{array}$ & $-\mathrm{CH}_{3},-\mathrm{CH}_{2}-$ & $v(\mathrm{C}-\mathrm{H})$ & 2,871 & \\
\hline $\begin{array}{l}\text { Methyl group, } \\
\text { Methylene group** }\end{array}$ & $-\mathrm{CH}_{3},-\mathrm{CH}_{2}-$ & $v(\mathrm{C}-\mathrm{H})$ & 2,963 & \\
\hline Vinyl group**** & $\mathrm{CH}_{2}=\mathrm{CH}-$ & $\gamma(\mathrm{C}-\mathrm{H})$ & 904 & \\
\hline Vinyl group**** & $\mathrm{CH}_{2}=\mathrm{CH}-$ & $\gamma(\mathrm{C}-\mathrm{H})$ & 988 & \\
\hline
\end{tabular}
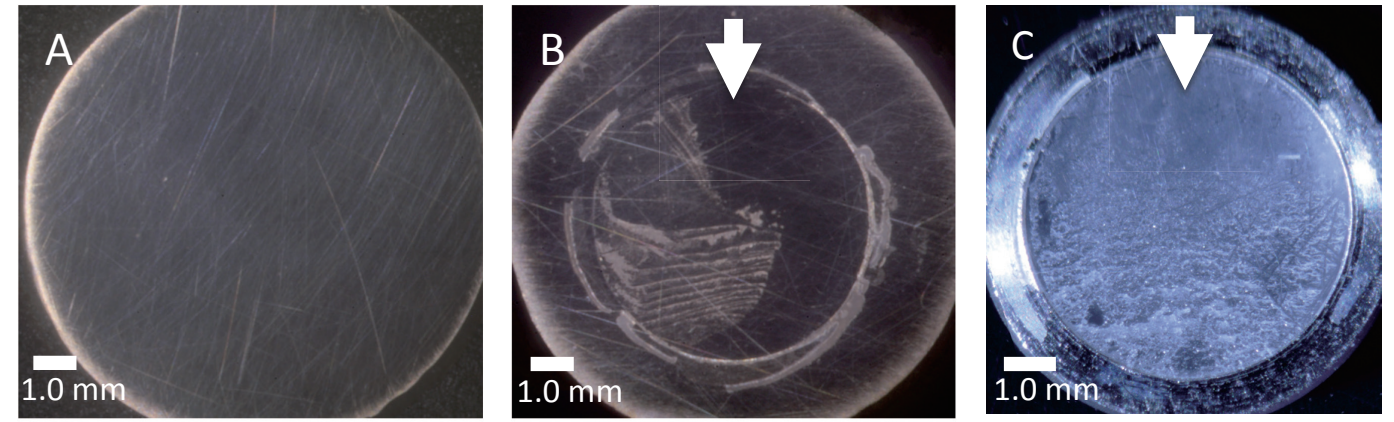

Fig. 3 Gold alloy specimens and debonded resin. (A) Polished gold alloy, (B) debonded surface of gold alloy treated with VTD primer before bonding, and (C) acrylic resin surface debonded from VTD-primed gold alloy. The white arrows indicate the direction of shearing. Digital photographic system: $(A$ and $B$ ) original magnification $\times 8,(C)$ original magnification $\times 10$.

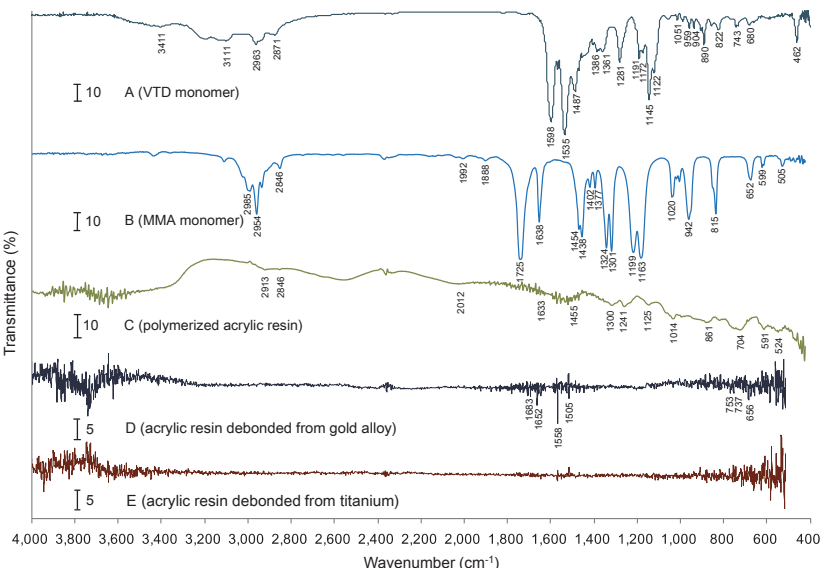

Fig. 4 IR spectra of (A) VTD, (B) MMA, (C) the polymerized acrylic resin block, (D) acrylic resin debonded from gold alloy primed with V-Primer, and (E) acrylic resin debonded from titanium primed with V-Primer. alloy and showed that VTD on the acrylic resin block from gold alloy has a thiol or thione-thiol structure.

Figure 5A shows the IR spectra of the MTU-6 monomer. Peaks at $1,331,1,157$, and $1,077 \mathrm{~cm}^{-1}$, due to $\mathrm{C}=\mathrm{S}$ stretching, can be observed (Table 5). The peak of the $\mathrm{C}=\mathrm{O}$ stretching of carbonyl group was at $1,718 \mathrm{~cm}^{-1}$ (Table 5). Additionally, peaks from N-H stretching and bending were observed at 3,440,3,148, and 1,652 $\mathrm{cm}^{-1}$ (Table 5). These IR spectra indicate that MTU-6 has a thione structure.

Figures 5B and 5C show the IR spectra of acrylic resin debonded from gold alloy and titanium. Peaks probably derived from MTU-6 were observed with the resin specimen debonded from gold alloy (Fig. 5B). The peaks at 1,558, 1,506, 1,456, 794, and $597 \mathrm{~cm}^{-1}$ are thus substantially identical with those of MTU-6 (Fig. 5A). 
Table 5 Band assignments for the IR spectra of MTU-6 and organic compounds

\begin{tabular}{|c|c|c|c|c|}
\hline \multirow{2}{*}{\multicolumn{3}{|c|}{ Assignment }} & \multicolumn{2}{|r|}{ Wavenumber $\left(\mathrm{cm}^{-1}\right)$} \\
\hline & & & MTU-6 & Acrylic resin debonded from gold alloy \\
\hline Pyrimidine $* * * * *$ & & $v(\mathrm{C}=\mathrm{C})$ & 1,558 & 1,558 \\
\hline Aromatic structure & & $v(\mathrm{C}=\mathrm{C})$ & 1,506 & 1,506 \\
\hline Aromatic structure* & & $v(\mathrm{C}-\mathrm{N})$ & 1,455 & 1,456 \\
\hline Pyrimidine $* * * * *$ & & $\gamma \mathrm{CH}$ & 791 & 794 \\
\hline Aromatic structure* & & $\delta(\mathrm{CNC})$ & 597 & 597 \\
\hline Amino group & $>\mathrm{NH}$ & $v(\mathrm{~N}-\mathrm{H})$ & 3,440 & \\
\hline Amino group $*, * *, * * *$ & $>\mathrm{NH}$ & $v(\mathrm{~N}-\mathrm{H})$ & 3,148 & \\
\hline Amino group & $>\mathrm{NH}$ & $\delta(\mathrm{N}-\mathrm{H})$ & 1,652 & 1,652 \\
\hline Amino group & $-\mathrm{C}=\mathrm{N}(+\mathrm{H})-$ & $v(\mathrm{C}=\mathrm{N})$ & & 1,683 \\
\hline Thiouredide & $-\mathrm{NH}-\mathrm{C}(=\mathrm{S})-$ & $v(\mathrm{C}=\mathrm{S})$ & 1,331 & \\
\hline Thiouredide** & $-\mathrm{NH}-\mathrm{C}(=\mathrm{S})-$ & $v(\mathrm{C}=\mathrm{S})$ & 1,157 & \\
\hline Thiouredide* & $-\mathrm{NH}-\mathrm{C}(=\mathrm{S})-$ & $v(\mathrm{C}=\mathrm{S})$ & 1,077 & \\
\hline Carbonyl group $*, * * * *$ & $>\mathrm{C}=\mathrm{O}$ & $v(\mathrm{C}=\mathrm{O})$ & 1,718 & 1,716 \\
\hline Methyl group $* *, * * * *$ & $-\mathrm{CH}_{3},-\mathrm{CH}_{2}-$ & $v(\mathrm{C}-\mathrm{H})$ & 2,934 & \\
\hline
\end{tabular}

These peaks were detected from $\mathrm{C}=\mathrm{C}, \mathrm{C}-\mathrm{N}$, and $\mathrm{C}-\mathrm{H}$ groups of MTU-6. Similarly, a peak representing $\mathrm{C}=\mathrm{O}$ stretching of the carbonyl group was seen at $1,716 \mathrm{~cm}^{-1}$ (Table 5). A peak caused by N-H bending at $1,652 \mathrm{~cm}^{-1}$ was observed, whereas peaks caused by $\mathrm{N}-\mathrm{H}$ stretching in MTU-6 (3,440 and 3,148 $\left.\mathrm{cm}^{-1}\right)$ were not seen. A new peak, at $1,683 \mathrm{~cm}^{-1}$, was found and was caused by $\mathrm{C}=\mathrm{N}$ stretching of MTU-6. These results suggest that MTU-6 in a resin block debonded from gold alloy has a thiol structure.

No trace of functional monomers was detected in resin specimens debonded from titanium.

\section{Discussion}

This study used spectral analysis to examine functional monomers remaining on debonded acrylic resin surfaces. To prevent contamination by foreign substances, such as brush fibers in the acrylic resin, each primer was dropped on the adhesive surface. Unreacted monomers remaining on the metal surface may affect the appearance of the IR spectrum for observation of the bonding mechanism, because excess VTD induces a chain transfer reaction with the resin monomer. Excess monomers were therefore removed by rinsing specimens with acetone. The acetone washing time was based on that described in a previous study, which found that VTD spectra depended on acetone washing time (10). For MTU-6, the effectiveness of acetone washing was confirmed in a previous study, which reported that MTU-6 was strongly adsorbed onto an Ag-Pd-Cu-Au alloy surface, even after repeated acetone cleaning (8).

Suzuki et al. used SERS spectroscopy to analyze the

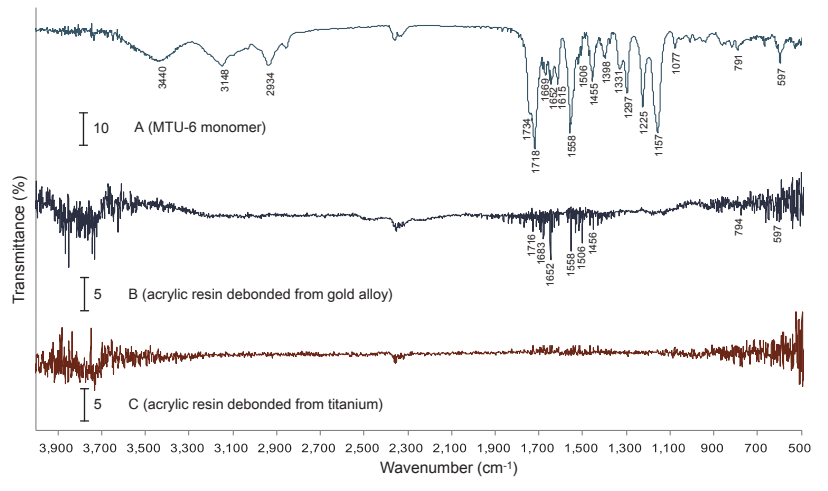

Fig. 5 IR spectra of (A) MTU-6, (B) acrylic resin debonded from gold alloy primed with Metaltite, and (C) acrylic resin debonded from titanium primed with Metaltite.

structure of VTD adsorbed to a colloidal gold surface (9). The results suggested that structural changes occurred within the VTD monomer upon adsorption to gold and transformed the $\mathrm{C}=\mathrm{S}$ bonds. The molecule appears to undergo thione-thiol tautomerization during adsorption. Using SERS spectroscopy and infrared reflection absorption spectroscopy, the same group later observed the same structural changes in VTD after adsorption to silver and copper (10). The previously reported triazine dithiol peak of VTD $\left(1,560 \mathrm{~cm}^{-1}\right)(10)$ was also found $(1,558$ $\mathrm{cm}^{-1}$ ) in the present study (Table 4), which suggests that the structure of the VTD monomer is thiol or thionethiol at the bonded interface between gold alloy and acrylic resin. No peak was detected at $462 \mathrm{~cm}^{-1}$, which represents the thioketone of VTD (16), perhaps because the transmission method of analysis yields considerable noise below $500 \mathrm{~cm}^{-1}$ when measuring acrylic resin.

The results for MTU-6 also showed a reduction in thione structure from the debonded acrylic resin block. 
Specifically, peaks including the $\mathrm{C}=\mathrm{S}$ bonds of thiouredides $\left(1,331,1,157\right.$, and $\left.1,077 \mathrm{~cm}^{-1}\right)(16)$ in the MTU-6 monomer were not clearly detected in the spectra of the debonded resin (Table 5). The peak at about 2,600 $\mathrm{cm}^{-1}$, attributable to S-H bonds, was not observed in MTU-6 or the debonded resin. Sulfur was involved in bonding to gold alloy, as indicated by attenuation of the $\mathrm{C}=\mathrm{S}$ bond peaks and the absence of the S-H bond peaks in the resin block. The decrease in peaks attributable to $\mathrm{N}-\mathrm{H}$ stretching $\left(3,440\right.$ and $\left.3,148 \mathrm{~cm}^{-1}\right)$ denotes a change in the amino group. The change in peaks attributable to $\mathrm{N}-\mathrm{H}$ stretching suggests a thiol structure forms after bonding to gold alloy. Spectral analyses indicate that MTU-6 likely has a thione structure. The structure tautomerizes to thiol during the priming process and contributes to the bonding of gold alloy and acrylic resin.

This study used titanium as the experimental control adherend. Bonding between titanium and acrylic resin was insufficient after application of the two thione primers. In addition, trace organic sulfur compounds were not detected in debonded resin specimens, because thione compounds do not adsorb onto titanium and are ineffective for bonding titanium.

In conclusion, VTD and MTU-6 were effective for enhancing bonding between gold alloy and tri- $n$ butylborane-initiated acrylic resin but were ineffective for bonding titanium. Infrared absorption spectroscopic analysis detected trace VTD, and MTU-6 remained on acrylic resin specimens debonded from gold alloy. VTD and MTU-6 in debonded resin had a thiol structure rather than a thione structure.

\section{Acknowledgments}

This study was supported in part by a grant from the Dental Research Center, Nihon University School of Dentistry (2015 and 2016).

\section{Conflict of interest}

None declared.

\section{References}

1. Mori K, Nakamura Y (1983) Study on triazine thiols. V. Polymerization of 6-(4-vinylbenzyl propyl)amino1,3,5-triazine-2,4-dithiol on copper plates and their corrosion resistance. J Polym Sci Polym Lett Ed 21, 889-895.

2. Atsuta M, Matsumura H, Tanaka T (1992) Bonding fixed prosthodontic composite resin and precious metal alloys with the use of a vinyl-thiol primer and an adhesive opaque resin. J Prosthet Dent 67, 296-300.

3. Matsumura H, Shimoe S, Nagano K, Atsuta M (1999) Effect of noble metal conditioners on bonding between prosthetic composite material and silver-palladium-copper-gold alloy. J
Prosthet Dent 81, 710-714.

4. Shimizu H, Takahashi Y (2008) Resin-bonded overcasting to salvage a long-span fixed prosthesis: a clinical report. J Prosthodont 17, 420-422.

5. Koizumi H, Ishii $T$, Naito $K$, Yoneyama $T$, Tanoue $N$, Matsumura H (2010) Effects of triazine dithione and hydrophobic phosphate monomers on bonding to $\mathrm{Ag}-\mathrm{Pd}-\mathrm{Cu}-\mathrm{Au}$ alloy and titanium with a methacrylic resin-based luting agent. J Adhes Dent 12, 215-222.

6. Nakamura M, Matsumura H (2013) Fifteen-year clinical performance of a resin-bonded fixed partial denture seated with a thione primer and a tri-n-butylborane-initiated luting agent. J Oral Sci 55, 263-266.

7. Yamashita M, Koizumi H, Ishii T, Nakayama D, Oba Y, Matsumura H (2013) Adhesive performance of silver-palladium-copper-gold alloy and component metals bonded with organic sulfur-based priming agents and a tri-n-butylborane initiated luting material. Acta Odontol Scand 71, 196-204.

8. Imai H, Koizumi H, Shimoe S, Hirata I, Matsumura H, Nikawa H (2014) Effect of thione primers on adhesive bonding between an indirect composite material and Ag-PdCu-Au alloy. Dent Mater J 33, 681-688.

9. Suzuki M, Fujishima A, Miyazaki T, Hisamitsu H, Kojima K, Kadoma Y (1999) A study on the adsorption structure of an adhesive monomer for precious metals by surface-enhanced Raman scattering spectroscopy. Biomaterials 20, 839-845.

10. Suzuki M, Yamamoto M, Fujishima A, Miyazaki T, Hisamitsu H, Kojima K et al. (2002) Raman and IR studies on adsorption behavior of adhesive monomers in a metal primer for $\mathrm{Au}$, $\mathrm{Ag}, \mathrm{Cu}$, and $\mathrm{Cr}$ surfaces. J Biomed Mater Res 62, 37-45.

11. Ohno H, Endo K, Yamane Y, Kawashima I (2001) XPS study on the weakest zone in the adhesion structure between resin containing 4-META and precious metal alloys treated with different surface modification methods. Dent Mater J 20, 90-102.

12. Silikas N, Wincott PL, Vaughan D, Watts DC, Eliades G (2007) Surface characterization of precious alloys treated with thione metal primers. Dent Mater 23, 665-673.

13. Kimura M, Aizawa M, Ohmori K, Iwamoto O (1998) Development of a new adhesive monomer for precious metals. J Dent Res 77, Spec Iss B 943. (Abstract)

14. Matsumura H, Yanagida H, Tanoue N, Atsuta M, Shimoe S (2001) Shear bond strength of resin composite veneering material to gold alloy with varying metal surface preparations. J Prosthet Dent 86, 315-319.

15. Yamashita M, Koizumi H, Ishii T, Furuchi M, Matsumura $H$ (2010) Evaluation of thiouracil-based adhesive systems for bonding cast silver-palladium-copper-gold alloy. J Oral Sci 52, 405-410.

16. Shtenberg BY, Mushkin YI, Finkel'shtein AI (1975) Calculation of the vibrational spectra of monothiocyanuric and dithiocyanuric acid. J Appl Spectrosc 23, 1370-1373.

17. Akyuz S, Akyuz T (2003) FT-IR spectroscopic investigation of adsorption of pyrimidine on sepiolite and montmorillonite from anatolia. J Incl Phenom Macrocycl Chem 46, 51-55. 